\title{
Vaginal Tubular Adenoma
}

National Cancer Institute

\section{Source}

National Cancer Institute. Vaginal Tubular Adenoma. NCI Thesaurus. Code C40257.

An adenoma that arises from the vagina and is characterized by a tubular architectural pattern. 